\title{
Metastatic Carcinoid Tumor
}

National Cancer Institute

\section{Source}

National Cancer Institute. Metastatic Carcinoid Tumor. NCI Thesaurus. Code C6431.

A carcinoid tumor that has extended beyond its original site of growth to other anatomic sites. 